\title{
Modulation of the response of prostate cancer cell lines to cisplatin treatment using small interfering RNA
}

\author{
EDUARDO PARRA $^{1}$ and JORGE FERREIRA ${ }^{2}$ \\ ${ }^{1}$ Laboratory of Experimental Biomedicine, University of Tarapaca, Campus Esmeralda, Iquique; ${ }^{2}$ Programme of \\ Molecular and Clinical Pharmacology, ICBM, Medical Faculty, University of Chile, Independencia, Santiago, Chile
}

Received March 29, 2013; Accepted May 23, 2013

DOI: $10.3892 /$ or.2013.2637

\begin{abstract}
Cisplatin is one of the most effective and widely used chemotherapeutic agents against several types of human cancers. However, the underlying mechanisms of action are not fully understood. We aimed to investigate the possible molecular mechanism(s) of acquired chemoresistance observed in prostate cancer cells treated with cisplatin. Human LNCaP cells (bearing wild-type p53) and PC-3 cells (lacking p53) were used. The expression levels of protein were determined by western blotting, and the mRNA levels were determined by reverse transcription-polymerase chain reaction (RT-PCR). Cell viability was measured by MTT assay, and the transcriptional effect of small interfering RNA (siRNA) was measured by luciferase reporter gene. We showed that cisplatin treatment increased JNK-1 and JNK-2 activity and expression in both LNCaP and PC-3 cells. In addition, the knockdown of JNK-1 expression by siRNA-JNK-1 or siRNA-JNK-2 significantly impaired the upregulation of AP-1 luciferase reporter gene, but failed to decrease the levels of AP-1 reporter gene expression induced by TPA treatment. Our observations indicate that JNK-1 and JNK-2 may be involved in the chemoresistance observed in prostate cancer cells treated with cisplatin and that blocking the stimulation of Jun kinase (JNK) signaling may be important for regulating the susceptibility to cisplatin of prostate cancer.
\end{abstract}

\section{Introduction}

The Jun kinase (JNK) pathway is a member of the mitogen-activated protein kinase (MAPK) pathways involved in signal transduction, and is an important cellular pathway associated with oncogenic transformation triggered in response to DNA damage $(1,2)$. JNK phosphorylates c-Jun (a component of the AP-1 transcription complex, consisting of heterodimers

Correspondence to: Dr Eduardo Parra Villegas, Laboratory of Experimental Biomedicine, University of Tarapaca, Campus Esmeralda, Avenida Luis Emilio Recabarren 2477, Iquique, Primera Región 001, Chile

E-mail: eparra@uta.cl

Key words: prostate cells, cisplatin, small interfering RNA of the Fos, Jun and ATF-2 family of proteins) on serine 63 and 73 in the N-terminal domain, thereby greatly enhancing transcriptional transactivation by c-Jun (3-5). Thus, phosphorylation of c-Jun at serines 63 and 73 leads to increased formation of the AP-1 complex consisting of c-Jun and a member of the Fos family of transcription factors or c-Jun in complex with $\mathrm{NH}_{2}$-terminal phosphorylated ATF-2. JNK activation has been correlated with apoptosis induced by death receptor activation (Fas and TNF- $\alpha$ ) and cellular stress (6-8). However, JNK is also activated by non-apoptotic stimuli $(8,9)$. In fact, JNK is strongly induced in response to a variety of DNA damaging treatments such as UV irradiation (10), DNA damaging chemotherapeutics such as cisplatin $(11,12)$, camptothecin (13) and etoposide (14), as well as epidermal growth factor (EGF) which causes rapid induction of both JNK and ERK signaling pathways $(15,16)$. The downmodulation of the EGF signaling pathway by EGF pre-treatment was found to inhibit UVB-induced JNK-1 activation (17). Members of these pathways have been the subject of intense interest in recent years owing to their role in mediating numerous growth factors and in responding to numerous agents and cytokines, in inflammatory stimuli and DNA damaging agents. Activation of the JNK pathway by any of the various upstream mechanisms leads to activation of central kinase, which acts directly on 3 major regulatory proteins, c-Jun, ATF-2 and Elk-1 by phosphorylating serine residues of activation domains which greatly increases their transcriptional (c-Jun, ATF-2) or DNA binding (Elk-1) potential. In fact, activation of the JNK pathway potentially influences the regulation of gene promoters bearing 7-bp AP-1 sites $(18,19)$. Several DNA repair genes that are known to be involved in cisplatin DNA adduct repair contain ATF/CREB regulatory elements in their promoters $(12,20)$. These genes are known to be activated by DNA damage and are of the type known to be activated by JNK. Indeed, several studies have shown that the JNK pathway is activated by DNA damaging chemotherapeutic agents such as cisplatin and that this pathway is required for repair of cisplatin DNA adducts $(12,21,22)$. It has been previously observed that the $\mathrm{NH}_{2}$-terminal $\mathrm{JNK}$ pathway is required for formation of a variety of human tumors both in vivo and in vitro $(2,23$ 25). It is known that the chemotherapeutic agent cisplatin, which damages DNA through the formation of bi-functional platinum adducts (25), activates JNK/SAPK up to 10-fold in a dose-dependent manner $(12,26)$. Nevertheless, activation 
of the JNK/SAPK pathway by genotoxic stress appears to be general. Several other well characterized DNA damaging agents have been shown to activate JNK/SAPK $(12,16,27-29)$. Thus, JNK is activated by cisplatin-induced DNA damage and is required for DNA repair and survival following cisplatin treatment $(12,30)$. Further evidence for the generality of the role of the JNK pathway in response to cisplatin comes from studies using a dominant-negative c-Jun $(3,4,31,32)$. To analyze the mechanisms of sensitivity of tumor cells to cisplatin by inhibition of the JNK-1/JNK-2 pathway, we tested whether small interfering RNA (siRNA) against Jnk-1 and Jnk-2 was able to induce loss of viability thereby sensitizing tumor cells to cisplatin. In the present study, we provide data showing that specific inhibition by siRNA led to a block in JNK-1/JNK-2 expression leading to loss of viability and cell growth arrest thereby sensitizing PC-3 and LNCaP prostate tumor cells to cisplatin treatment.

\section{Materials and methods}

The protease inhibitors, phenylmethylsulfonyl fluoride (PMSF), leupeptin, pepstatin, aprotinin and bestatin, were purchased from Roche (San Francisco, CA, USA). $\left[\gamma-{ }^{32} \mathrm{P}\right] \mathrm{ATP}$ was purchased from Amersham Pharmacia Biotech (Piscataway, NJ, USA). T4 polynucleotide kinase and poly $(\mathrm{dI}-\mathrm{dC})_{20}$ were obtained from Amersham. Tris-borate-EDTA buffer and acrylamide-bisacrylamide (29:1) were obtained from Bio-Rad (Richmond, CA, USA). Luciferase assay reagent, lysis buffer and the pGL2 luciferase vector were obtained from Promega Corporation (Madison, WI, USA). Phorbol 12-myristate 13-acetate (TPA) was purchased from Strategene Inc. (La Jolla, CA, USA). Anti-c-Jun, -JNK, -JNK-1, -JNK-2 and - $\beta$-actin antibodies were purchased from Santa Cruz Biotechnology, Inc. (Santa Cruz, CA, USA). TPA luciferase assay reagent, lysis buffer and the pGL2/pGL3 luciferase vector were obtained from Promega. GST-c-Jun (1-79) was a gift from Dr Roger Davis (Howard Hughes Medical Institute, Chevy Chase, MA, USA). Cisplatin and transplatin were purchased from Sigma Chemical Co. (St. Louis, MO, USA).

Cell lines and culture. Human prostate carcinoma cell lines PC-3 and LNCaP were a gift from Dr Dan Mercola (The SKCC, La Jolla, CA, USA). The cells were cultured in RPMI-1640 medium supplemented with $100 \mathrm{ml} / \mathrm{l}$ fetal bovine serum (FBS), 8x10 $5 / 1$ penicillin and $0.1 \mathrm{~g} / 1$ streptomycin in a humidified incubator containing $50 \mathrm{ml} / 1 \mathrm{CO}_{2}$ at $37^{\circ} \mathrm{C}(14,15)$. The antibodies used for western blotting included those against protein kinase JNK-1, JNK-2, (Santa Cruz Biotechnology, Inc) and $\beta$-actin (Sigma Chemical Co.). Western blot analysis was performed as previously described (33).

siRNA preparation and transfection of small interfering $R N A$. siRNA oligonucleotides with two thymidine residues $(\mathrm{tt})$ at the 3 '-end of the sequence were designed for JNK-1 (sense, 5'-AAG CCCAGTAATATAGTAGTA and antisense, 5'-TACTACTA TATTACTGGGC-3') and JNK-2 (sense, 5'-CATGATGTT ATCATATCTTAT-3' and antisense, 5'-ATAAGATATG ATAACATCATG-3'). Cells were treated in parallel with a non-silencing siRNA (sense, 5'-AATTCTCCGAACGTGT
CACGT-3' and antisense, 5'-ACGTGACACGTTCGGAGA ATT-3') as control. Oligonucleotides were synthesized by Shanghai Genechem Co. Ltd. The cells were cultured in medium without antibiotics, and $24 \mathrm{~h}$ before transfection resulting in a confluence of the cell monolayer by $60-80 \%$. Jnk-1-siRNA and Jnk-2-siRNA or non-silencing siRNA (70 nmol) were mixed with Lipofectamine ${ }^{\mathrm{TM}} 2000$ (Invitrogen Life Technologies, Carlsbad, CA, USA) according to the manufacturer's recommendation and added to the cells. After $6 \mathrm{~h}$ at $37^{\circ} \mathrm{C}$, the medium was replaced and the cells were cultivated in RPMI-1640 supplemented with $10 \%$ heat-inactivated FBS $(33,34)$.

Western immunoblot analysis. PC-3 and LNCaP prostate carcinoma cells lines $\left(5 \times 10^{5}\right)$ were seeded onto 6 -well plates. Forty-eight hours after transfection, cells were collected and washed twice by cold PBS, and each well was treated with $50 \mathrm{ml}$ lysis buffer $(2 \mathrm{mmol} / \mathrm{l}$ Tris- $\mathrm{HCl}, \mathrm{pH} \mathrm{7.4,} 50 \mathrm{mmol} / \mathrm{l}$ $\mathrm{NaCl}, 25 \mathrm{mmol} / 1$ EDTA, $50 \mathrm{mmol} / 1 \mathrm{NaF}, 1.5 \mathrm{mmol} / 1 \mathrm{Na}_{3} \mathrm{VO}_{4}$, $1 \%$ Triton $\mathrm{X}-100,0.1 \% \mathrm{SDS}$, supplemented with protease inhibitors $1 \mathrm{mmol} / 1$ phenylmethylsulfonyl fluoride, $10 \mathrm{mg} / 1$ pepstatin, $10 \mathrm{mg} / \mathrm{l}$ aprotinin and $5 \mathrm{mg} / \mathrm{l}$ leupeptin) (all from Sigma-Aldrich, St. Louis, MO, USA). Protein concentrations were determined using the Bradford protein assay. Equal amounts of protein $(50 \mu \mathrm{g})$ were separated on a $15 \%$ SDS polyacrylamide gel and transferred to nitrocellulose membranes (Hybond C; Amersham, Freiburg, Germany). Membranes were blocked in 5\% non-fat dry milk in TBS for $1 \mathrm{~h}$ at room temperature and probed with rabbit anti-JNK-1 (sc-1648) and anti-JNK-2 (sc-571) antibodies (dilution, 1:500) overnight at $4^{\circ} \mathrm{C}$. After 3 washings with TBS containing $0.1 \%$ Tween-20, membranes were incubated with anti-rabbit IgG-horseradish peroxidase (1:5,000; Santa Cruz Biotechnology, Inc.), and developed by luminal mediated chemiluminescence (Appylgen Technologies, Inc., China). To confirm equal protein loading, membranes were reprobed with a 1:1,000 dilution of an antiactin antibody (Santa Cruz Biotechnology, Inc.). Densitometric analyses were performed using Scion Image software (35).

Reverse transcription-polymerase chain reaction (RT-PCR). $\mathrm{PC}-3$ and LNCaP prostate carcinoma cell lines $\left(5 \times 10^{5}\right)$ were seeded onto 6-well plates. Total RNA was extracted $48 \mathrm{~h}$ after transfection using TRIzol reagent. Reverse transcription was performed using One Step RT-PCR kit. The primers included Jnk-1, 5'-CGTCTGGTGGAAGGAGAGAG-3' (forward primer) and 5'-TAATAACGGGGGTGGAGGAT-3' (reverse primer); Jnk-2, 5'-TCTGACGTCCTGGGCTGGAC-3' (forward primer) and 5'-GCAGCAGCCCTCAGGATCCT-3' (reverse primer); human $\beta$-actin, 5'-TCACCAACTGGGACGA CAT-3' (forward primer) and 5'-GAAGTCCAGGGCGACG TAG-3' (reverse primer). Thermal cycling conditions were as follows: $42^{\circ} \mathrm{C}$ for $30 \mathrm{~min}, 94^{\circ} \mathrm{C}$ for $2 \mathrm{~min}$, followed by 28 cycles of $94^{\circ} \mathrm{C}$ for $15 \mathrm{sec}, 55^{\circ} \mathrm{C}$ for $30 \mathrm{sec}, 72^{\circ} \mathrm{C}$ for $1 \mathrm{~min}$, with a final extension at $72^{\circ} \mathrm{C}$ for $10 \mathrm{~min}$. RT-PCR products were visualized by ethidium bromide-stained agarose gels and the images were scanned using a UV light.

Kinase assays (JNK-1 activity). Cells were incubated in the absence of serum for $16 \mathrm{~h}$ and then treated with various agents. They were then washed twice with PBS and lysed 

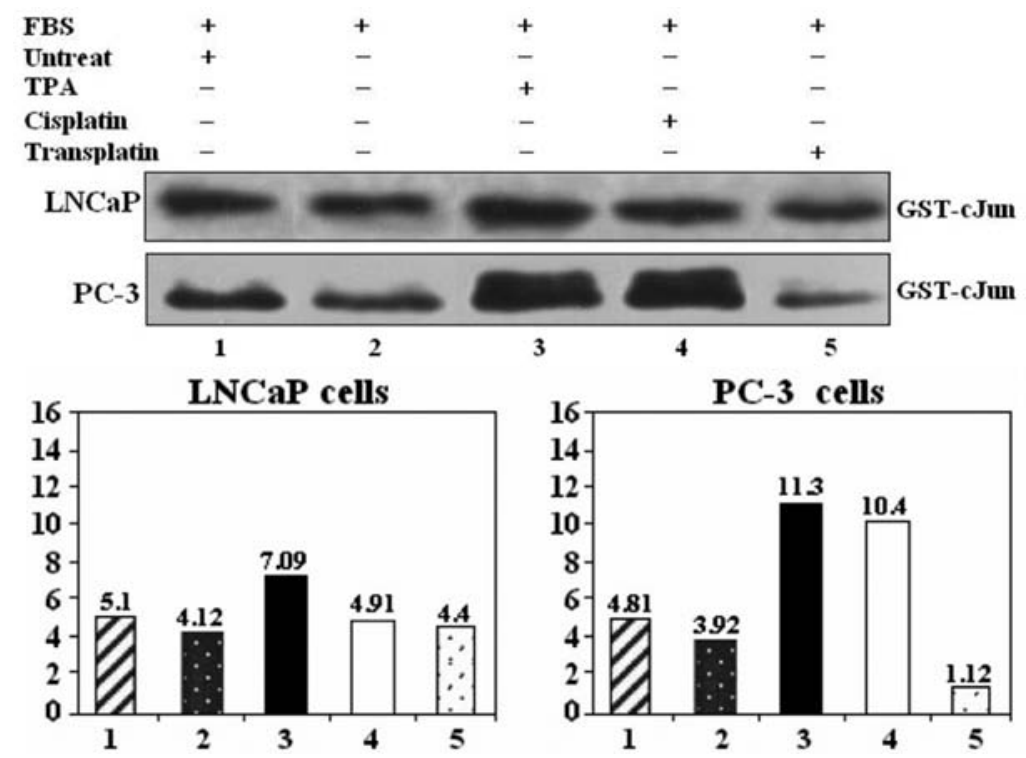

Figure 1. JNK-1 activity in LNCaP and PC-3 prostate carcinoma cell lines. To determine if TPA or cisplatin activates the Jun kinase (JNK) pathway in LNCaP and PC-3 cells, the cells were grown in 10\% FBS and treated either with cisplatin $(300 \mu \mathrm{g} / \mathrm{ml})$ or TPA $(30 \mathrm{nM})$ or with transplatin as control. JNK-1 activity was examined $1 \mathrm{~h}$ after treatment, by immunocomplex kinase assay measuring the phosphorylation of GST-c-Jun (1-79). Numbers on the top of each bar indicate relative amounts of JNK-1 activity obtained for each treatment, compared to levels of JNK-1 activity obtained in untreated cells. TPA and cisplatin induced JNK-1 activation, compared to the untreated state of prostate cells. One of 3 similar experiments is shown.

in ice-cold lysis buffer (20 mM HEPES, pH 7.4, $150 \mathrm{mM}$ $\mathrm{NaCl}, 1 \%$ Triton $\mathrm{X}-100,1.5 \mathrm{mM} \mathrm{MgCl}_{2}, 1 \mathrm{mM}$ EDTA, $1 \mathrm{mM}$ EGTA, $2.5 \mathrm{mM}$ sodium pyrophosphate, $1 \mathrm{mM} \beta$-glycerol phosphate, $1 \mathrm{mM}$ sodium orthovanadate, $1 \mu \mathrm{g} / \mathrm{ml}$ leupeptin and $1 \mathrm{mM}$ phenylmethylsulfonyl fluoride). The extracts were centrifuged to remove cellular debris, and the protein content of the supernatants was determined using the Bio-Rad protein assay reagent. Protein $(100 \mu \mathrm{g})$ from the lysate samples was incubated at $4^{\circ} \mathrm{C}$ overnight with the $\mathrm{N}$-terminal c-Jun (1-79) and ATF-2-glutathione S-transferase fusion protein bound to glutathione-Sepharose beads in order to selectively precipitate JNK-1 and p38 from the cell lysates. Next, the beads were washed to remove non-specifically bound proteins. Then, the kinase reaction was carried out in the presence of cold ATP, and samples were resolved on $12 \%$ SDS-gel electrophoresis followed by western blotting with the phospho-specific c-Jun antibody. This antibody specifically recognizes JNK-1-induced phosphorylation of c-Jun at Ser63, a site important for c-Jun-dependent transcriptional activity (36).

Cell toxicity assay (MTT). The effect of cisplatin on antitumor activity in human LNCaP and PC-3 prostate carcinoma cells was determined by the MTT survival assay, or using a commercial MTT assay kit (CellTiter $96^{\circledR}$ AQueous One Solution cell proliferation assay; Promega Corporation) according to the manufacturer's instructions. The MTT survival assay was performed as described previously (37). The MTT assay is a commonly used method to evaluate cell survival, based on the ability of viable cells to convert 3-(4,5-dimethylthiazole2-yl)-2,5 diphenyltetrazolium bromide (MTT), a soluble tetrazolium salt, into an insoluble formazan precipitate, which is quantitated by spectrophotometry following solubilization in dimethyl sulfoxide (DMSO). Briefly, LNCaP and PC-3 cells untreated and treated with cisplatin alone, or the combination of siRNA and cisplatin in 96-well tissue culture dishes were incubated with MTT ( $2 \mathrm{mg} / \mathrm{ml})$ for $4 \mathrm{~h}$. The cells were then solubilized in $125 \mathrm{ml}$ of DMSO, and absorbance readings were taken using a 96-well Opsys $\mathrm{MR}^{\mathrm{TM}}$ microplate reader (Thermo/Labsystems, Chantilly, VA, USA). The amount of MTT dye reduction was calculated based on the difference between absorbance at 570 and $630 \mathrm{~nm}$. Cell viability in treated cells was expressed as the amount of dye reduction relative to that of the untreated control cells. The wells which contained only medium and $10 \mathrm{ml}$ of MTT were used as blanks for the plate reader. Three sets of experiments were performed in 8-12 wells for each treatment.

\section{Results}

The ability to turn off individual genes at will in growing cells provides a powerful tool for elucidating the role of a particular gene and for therapeutic intervention when that gene is overexpressed or mutated. Since the discovery of siRNAs as the key mediators of RNA-induced gene silencing, they have been applied to inhibit the expression of a wide variety of target genes. Two of them, the Jnk-1 and Jnk-2 genes expressing the respective kinases with important functions in the regulation of growth and differentiation, are involved in the transformed phenotype of several types of cancers.

TPA and cisplatin activate the JNK-1 pathway in PC-3 and LNCaP prostate carcinoma cell lines. c-Jun- $\mathrm{NH}_{2}$ kinase (JNK) is among the protein kinases that play an important role in cellular stress response via the phosphorylation of c-Jun, ATF-2 and p53. Activation of JNK-1 by UV irradiation requires cooperation between membrane and nuclear components, including DNA lesions per se. To determine whether TPA and cisplatin activate the JNK pathway in PC-3 and LNCaP cells, cells were cultured in $10 \%$ PBS and treated with different stimuli (Fig. 1) such as TPA (30 nM), cisplatin $(300 \mu \mathrm{g} / \mathrm{ml})$ and 


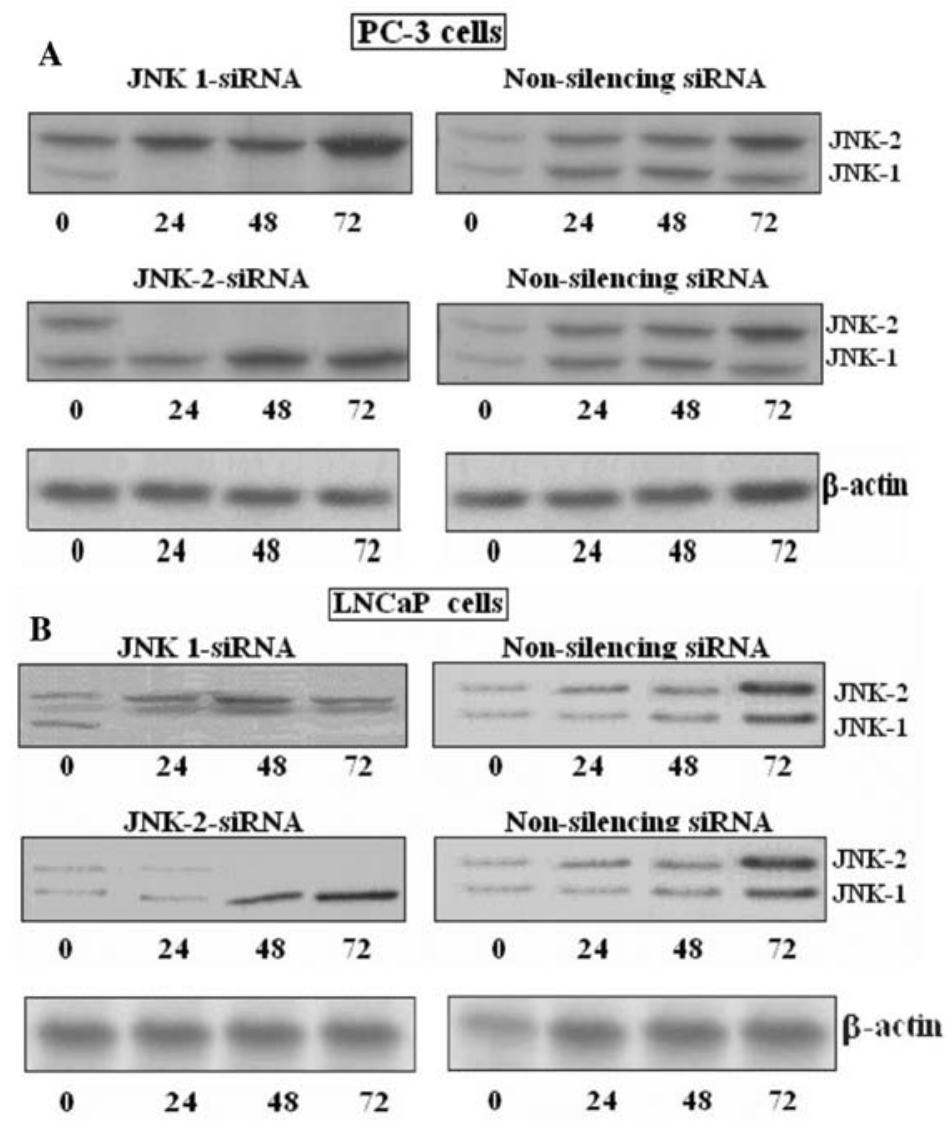

Figure 2. JNK-1-siRNA and JNK-2-siRNA specifically inhibit protein expression of JNK-1 and JNK-2, respectively. Western blot analysis of (A) PC-3 and (B) LNCaP prostate carcinoma cell lines at various times after transfection with the indicated amount of either siRNA-Jnk-1 or siRNA-Jnk-2. Non-silencing siRNA was used as the control. The western blot transfer confirmed the specificity of JNK-1 and JNK-2 siRNAs, whereas non-silencing siRNA did not eliminate the expression of either protein. One of 3 similar experiments is shown.

transplatin as the control. JNK-1 activity was measured $1 \mathrm{~h}$ after the treatments, as described in Materials and methods. Results showed that addition of TPA and cisplatin activated JNK-1 and JNK-2 activities, while transplatin did not have any effect in inducing JNK activity (Fig. 1).

Jnk-1-siRNA and Jnk-2-siRNA specifically inhibit the expression of JNK-1 and JNK-2 protein, respectively. In order to determine whether a causal link exists between JNK activity and protein expression, we used specific siRNAs against JNK-1 and JNK-2 complementary to mRNA sequences common to either JNK-1 or JNK-2. To examine the specific effect of the abovementioned siRNAs on prostate cancer cells, the proteins and mRNA levels were determined by western blotting and RT-PCR analysis, respectively. Results are displayed in Fig. 2A and B. JNK-1 and JNK-2 protein and mRNA were strongly expressed in the LNCaP prostate carcinoma cell lines as reflected by western blotting. JNK-1 and JNK-2 protein expression was strongly inhibited by siRNA against the named kinases. The inhibition was completely compared with the control or non-silencing siRNA.

Semi-quantitative analysis of JNK-1 and JNK-2 mRNA expression by RT-PCR in human PC-3 and LNCaP prostate carcinoma cell lines. JNK-1, JNK-2 and $\beta$-actin in the indicated cell lines was analyzed by RT-PCR, and ethidium bromide stained agarose gels are shown. PC-3 cells were either untreated (lane 1), treated with cisplatin (lane 2), treated with non-silencing siRNA (lane 3) or treated with siRNA-JNK-1 or siRNA-JNK-2 (lane 4) (Fig. 3A). LNCaP cells were also untreated (lane 1), treated with cisplatin (lane 2), treated with non-silencing siRNA (lane 3) and treated with siRNA-JNK-1 or siRNA-JNK-2 (lane 4) (Fig. 3B). Cisplatin was able to markedly increase the mRNA expression of JNK-1 and JNK-2 in both PC-3 and LNCaP cell lines. Non-silencing siRNA did not have any effect on the expression of mRNA. Moreover, siRNAs against JNK-1 and JNK-2 were able to decrease the expression of mRNA in both PC-3 and LNCaP prostate carcinoma cell lines. The integrity of each RNA sample was confirmed by using primers to the human $\beta$-actin gene (Fig. $3 \mathrm{~A}$ and $\mathrm{B}$ bottom lanes).

Transfection with siRNA-JNK-1 and siRNA-JNK-2 blocks the effect of TPA (30 nM) and cisplatin on the transcriptional activity of the reporter gene. To show that the blocking of JNK-1/JNK-2 activity inhibits the activation of promoters bearing a tandem repeat of AP-1 response elements, transient transfection studies were carried out using a reporter construct bearing the consensus or classic AP-1 site repeated in tandem $(4 \mathrm{x})$ driving expression of a luciferase reporter gene. Expression of this reporter in untreated or PC-3 and LNCaP cells transfected with non-silencing siRNA (Fig. 4) 

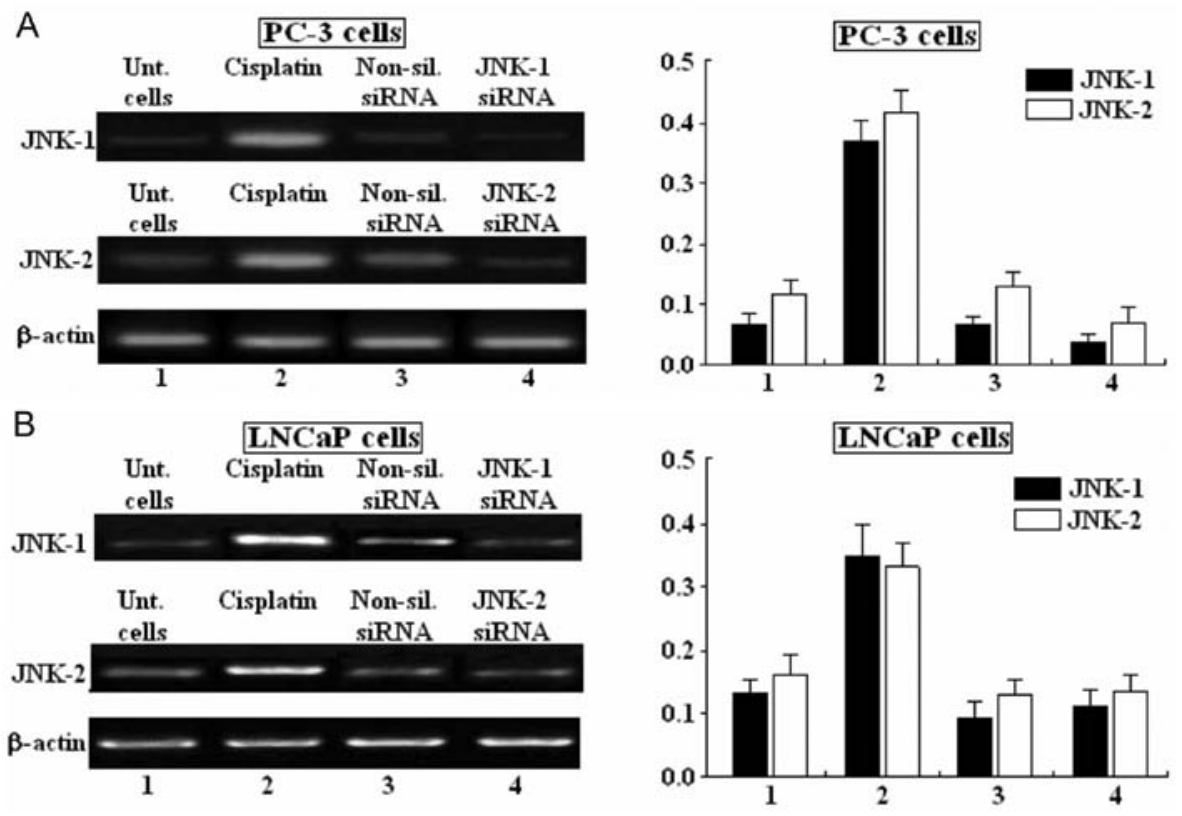

Figure 3. RT-PCR analysis of JNK-1 and JNK-2. Expression of JNK-1, JNK-2 and $\beta$-actin in (A) PC-3 and (B) LNCaP cell lines was analyzed by RT-PCR, and ethidium bromide stained agarose gels are shown. Lane 1, untreated PC-3 or LNCaP cells; lane 2, cells treated with cisplatin; lane 3, cells treated with non-silencing siRNA and lane 4, cells treated with siRNA-JNK-1 or siRNA-JNK-JNK-2. One of 2 similar experiments is shown.

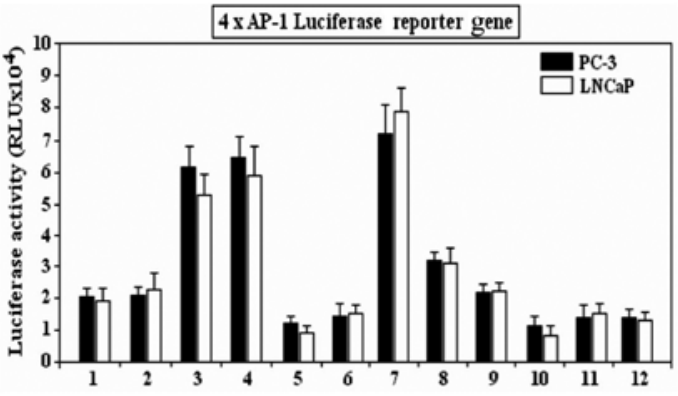

Figure 4. Inhibition of AP-1-dependent transcription induced by TPA and cisplatin stimulation, by siRNA against JNK-1 (JNK-1-siRNA). The reporter, which contains $4 \mathrm{x}$ AP-1 response elements in tandem directing expression of the luciferase gene, was transfected into PC-3 or LNCaP cells. The graph shows luciferase activity compared to the controls with a reporter lacking the AP-1 sites. The AP-1 reporter requires an activated c-Jun and was, therefore, activated by increased expression of JNK-1. The reporters were inhibited by Jnk-1-siRNA. Bar 1, untreated cells; 2, non-silencing siRNA; 3, TPA (30 nM); 4, cisplatin; 5, JNK-1-siRNA; 6, JNK-2-siRNA; 7, TPA + cisplatin; 8, TPA + JNK-1-siRNA; 9, TPA + JNK-2-siRNA; 10, cisplatin + JNK-1-siRNA; 11, cisplatin + JNK-2-siRNA; 12, JNK-1-siRNA/JNK-2-siRNA.

led to little activation, whereas TPA (30 $\mathrm{nM})$ and cisplatin treatment strongly enhanced expression of this reporter. The TPA or cisplatin-induced expression of the reporter gene was inhibited following transfection with siRNA-JNK-1, suggesting that siRNA against JNK-1 enhances the sensitivity of PC-3 and LNCaP for cisplatin. However, TPA in the presence of JNK-1-siRNA (bar 8, Fig. 4) was unable to reverse the inhibitory effects of JNK-1-siRNA (bar 5, Fig. 4) compared with the effect of TPA alone (bar 3, Fig. 4), and observed in the transcriptional activity expressed as luciferase activity (Fig. 4). The results are consistent with the fact that activation of the JNK pathway leads to phosphorylation of at least 3 prin-

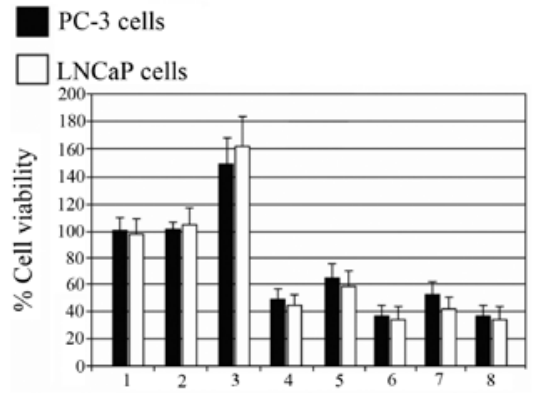

Figure 5. JNK knockout sensitizes cells to DNA damage-induced death MTT assay. Cells were seeded in 24-well plate, and either untreated or treated with indicated stimuli in triplicate. Cells were exposed to MTT reagent (as described in Materials and methods) for colorimetric detection of viable cells. Data are expressed as the percentage of cell viability. Bar 1, untreated cells; 2, non-silencing siRNA; 3, cisplatin; 4, JNK-1-siRNA; 5 , JNK-2-siRNA; 6, cisplatin + JNK-1-siRNA; 7, cisplatin + JNK-2-siRNA; 8, JNK-1-siRNA + JNK-2-siRNA.

cipal transcription factor including Elk-1, ATF-1 and c-Jun. Thus, phosphorylation of c-Jun at serines 63 and 73 leads to increased formation of AP-1 complexes consisting of c-Jun and a member of the Fos family of transcription factors.

siRNA-JNK-1/2 increases the sensitivity of $P C-3$ and LNCaP cells to the antiproliferative effect of cisplatin. In light of the important role of JNK in the antitumor action of cisplatin, we hypothesized that concurrent inhibition of JNK-1/JNK-2 signaling by siRNAs could sensitize PC-3 and $\mathrm{LNCaP}$ cisplatin-resistant cells to the antiproliferative activity of this chemotherapeutic drug. To test this hypothesis, PC-3 and LNCaP cells were exposed to an indicated concentration of cisplatin $(300 \mu \mathrm{g} / \mathrm{ml})$ alone or in combination with siRNA-JNK-1 and siRNA-JNK-2 for 48 h. Fig. 5 demonstrates the ability of JNK-1 and JNK-2 siRNAs to 
improve the sensitivity of PC-3 and LNCaP cells to cisplatininduced cell death. Cisplatin alone caused an increase in viability of $\sim 40$ and $50 \%$ (lane 3), respectively; a reduction in cell viability was observed after siRNA-JNK-1 or siRNAJNK-2 treatment (lanes 4 and 5). Further reduction in cell viability was observed in cells treated with both cisplatin and siRNA-JNK-1 or siRNA-JNK-2 (lanes 6 and 7) and the combination of siRNA-JNK-1 and siRNA-JNK-2 achieved $\sim 63 \%$ cell death (lane 8 ), similar to either, siRNA-JNK-1 or siRNA-JNK-2. Notably, siRNA against Jnk-1 or Jnk-2 was able to overcome the resistance of PC-3 and LNCaP cells to cisplatin.

\section{Discussion}

We analyzed the role of the JNK pathway to mediate cisplatindriven transformation in prostate carcinoma cell lines. To test the transforming role of JNK in prostate carcinoma, we examined two prostate cell lines, PC-3 and LNCaP. We employed siRNAs that abrogated the expression of either JNK-1 or JNK-2. siRNA methods were applied in vitro and confirmed that inhibition of the JNK pathway blocked expression of the transformed phenotype as manifested by activity, protein expression, mRNA, transcription and cell viability. It has been demonstrated that the kinases JNK-1 and JNK-2 are expressed in a high proportion of most types of human cancers, including breast, prostate, gastrointestinal cancer, lymphoma, melanoma and myeloid leukemia (38-40). Expression of the nonphosphorylatable mutant, c-Jun $63-73$, reduces growth by $30-50 \%$ in human tumor cells $(42,43)$ and the altered expression of JNK-1 or JNK-2 seems to define a common event associated with pathogenesis (44). Although some studies previously revealed that the effects of inactivation of JNK-1 and JNK-2 in some cell lines were modest (45), other groups using different approaches to reduce the protein levels, found that a decrease in JNK-1 and JNK-2 expression inhibited the growth of several types of tumor cells, including breast tumor cells. In fact, the oncogenic role of JNK has been recognized in human breast cancer cells $(23,46)$, such as the mediation of the transformation by Bcr-Abl (46). In this study, we observed that treatment of serum-stimulated prostate carcinoma cells with siRNA-JNK-1 was more effective than siRNA-JNK-2. In contrast, treatment with siRNA-JNK-2 had little effect on both PC-3 and LNCaP cells similar to treatment with the non-silencing siRNA or the untreated cells. These results are in agreement with other studies which demonstrated the role of the JNK pathway and its effect on several types of human cancers (27-29) including the observations suggesting that the JNK/SAPK pathway may play a major role in the transformation process $(43,44)$. Our results demonstrated that siRNAs can effectively downregulate the endogenous JNK-1 or JNK-2 expression with great specificity. This downregulation may involved the participation of several genes, demonstrating autoregulation of the pathway since c-Jun is known to be activated by genotoxic stress, including cisplatin (45). As JNK inhibition by siRNA results in decreased activation and expression of JNK-1 and JNK-2, we next determined the effect of JNK inhibition on AP-1 activation by transfection of the AP-1-luciferase plasmid, which contains four tandem copies of the AP-1 consensus sequence. Since activation of the JNK pathway leads to phosphorylation of at least 3 principal transcription factors including Elk-1, ATF-1 and c-Jun, we aimed to ascertain whether siRNAs against JNK-1 and JNK-2 affect the transcriptional activity of c-Jun. As we know, phosphorylation of c-Jun at serines 63 and 73 leads to increased formation of AP-1 complexes consisting of c-Jun and a member of the Fos family of transcription factors $(3,4,31,46)$. Thus, transient transfection of 4x AP-1-luciferase in PC-3 and LNCaP cells treated with either TPA or cisplatin significantly increased AP-1 reporter activity, but this increase in transcription activity was strongly reversed by JNK-1-siRNA, but only partially by JNK-2-siRNA. Similarly, a viability assay showed that cell transfection with either JNK-1-siRNA or JNK-2-siRNA was able to induce growth arrest in cells treated with cisplatin. Given the fact that it has been previously demonstrated that inhibition of c-Jun by a dominant-negative c-Jun sensitizes cells to cisplatinum toxicity $(3,4,31)$ and that JNK-1 and JNK-2 is upstream on c-Jun in the JNK pathway, it is reasonable to believe that these small interfering RNAs would be effective in sensitizing resistant cells to chemotherapeutic treatment. In summary, the present results suggest that blocking the JNK pathway may increase cisplatin sensitivity in PC-3 and LNCaP prostate carcinoma cell lines. Moreover, an optimum result was observed for siRNA-JNK-1 treatment in both PC-3 and LNCaP cells.

\section{Acknowledgements}

We thank Dr Dan Mercola (The Sidney Kimmel Cancer Center, San Diego, CA, USA) for providing the prostate cell lines PC-3 and LNCaP, and for providing us with the vector for expressing Jnk-1. This study was supported by the Laboratory of Experimental Biomedicine, University of Tarapaca, UTA, Chile.

\section{References}

1. Davis RJ: Signal transduction by the JNK group of MAP kinases. Cell 103: 239-252, 2000.

2. Kralova J, Sheely JI, Liss AS and Bose HR Jr: ERK and JNK activation is essential for oncogenic transformation by v-Rel. Oncogene 29: 6267-6279, 2010.

3. Binétruy B, Smeal T and Karin M: Ha-Ras augments c-Jun activity and stimulates phosphorylation of its activation domain. Nature 351: 122-127, 1991.

4. Smeal T, Binétruy B, Mercola DA, Birrer M and Karin M: Oncogenic and transcriptional cooperation with Ha-Ras requires phosphorylation of c-Jun on serines 63 and 73. Nature 354: 494-496, 1991.

5. Mechta F, Lallemand D, Pfarr CM and Yaniv M: Transformation by ras modifies AP1 composition and activity. Oncogene 14: 837-847, 1997.

6. Minden A and Karin M: Regulation and function of the JNK subgroup of MAP kinases. Biochim Biophys Acta 1333: F85-F104, 1997.

7. Verheij M, Ruiter GA, Zerp SF, van Blitterswijk WJ, Fuks Z, Haimovitz-Friedman A and Bartelink $H$ : The role of the stress-activated protein kinase (SAPK/JNK) signaling pathway in radiation-induced apoptosis. Radiother Oncol 47: 225-232, 1998.

8. Paul A, Wilson S, Belham CM, Robinson CJ, Scott PH, Gould GW and Plevin R. Stress-activated protein kinases: activation, regulation and function. Cell Signal 9: 403-410, 1997.

9. Gupta S, Barrett T, Whitmarsh AJ, Cavanagh J, Sluss HK, Dérijard B and Davis RJ: Selective interaction of JNK protein kinase isoforms with transcription factors. EMBO J 15: 2760-2770, 1996. 
10. Adler V, Fuchs SY, Kim J, Kraft A, King MP, Pelling J and Ronai $\mathrm{Z}$ : jun- $\mathrm{NH}_{2}$-terminal kinase activation mediated by UV-induced DNA lesions in melanoma and fibroblast cells. Cell Growth Differ 6: 1437-1446, 1995.

11. Amdjadi K and Sefton BM: Ultraviolet light-induced stimulation of the JNK mitogen-activated protein kinase in the absence of src family tyrosine kinase activation. J Biol Chem 275: 22520-22525, 2000.

12. Potapova O, Haghighi A, Bost F, Liu C, Birrer MJ, Gjerset R and Mercola D: The Jun kinase/stress-activated protein kinase pathway functions to regulate DNA repair and inhibition of the pathway sensitizes tumor cells to cisplatin. J Biol Chem 272 14041-14044, 1997.

13. Saleem A, Datta R, Yuan ZM, Kharbanda S and Kufe D Involvement of stress-activated protein kinase in the cellular response to 1- $\beta$-D-arabinofuranosylcytosine and other DNA-damaging agents. Cell Growth Differ 6: 1651-1658, 1995.

14. Osborn MT and Chambers TC: Role of the stress-activated/c-Jun $\mathrm{NH}_{2}$-terminal protein kinase pathway in the cellular response to adriamycin and other chemotherapeutic drugs. J Biol Chem 271: 30950-30955, 1996.

15. Hashimoto A, Kurosaki M, Gotoh N, Shibuya M and Kurosaki T: Shc regulates epidermal growth factor-induced activation of the JNK signaling pathway. J Biol Chem 274: 20139-20143, 1999.

16. Bost F, McKay R, Dean N and Mercola D: The JUN kinase/stressactivated protein kinase pathway is required for epidermal growth factor stimulation of growth of human A549 lung carcinoma cells. J Biol Chem 272: 33422-33429, 1997.

17. Kang SA, Lee ES, Yoon HY, Randazzo PA and Lee ST: PTK6 inhibits down-regulation of EGF receptor through phosphorylation of ARAP1. J Biol Chem 285: 26013-26021, 2010.

18. van Dam H, Wilhelm D, Herr I, Steffen A, Herrlich P and Angel P: ATF-2 is preferentially activated by stress-activated protein kinases to mediate $\mathrm{c}$-jun induction in response to genotoxic agents. EMBO J 14: 1798-1811, 1995.

19. Pulverer BJ, Kyriakis JM, Avruch J, Nikolakaki E and Woodgett JR: Phosphorylation of c-jun mediated by MAP kinases. Nature 353: 670-674, 1991.

20. Tanabe M, Izumi H, Ise T, Higuchi S, Yamori T, Yasumoto K and Kohno K: Activating transcription factor 4 increases the cisplatin resistance of human cancer cell lines. Cancer Res 63: 8592-8595, 2003.

21. Crul M, Schellens JH, Beijnen JH and Maliepaard M: Cisplatin resistance and DNA repair. Cancer Treat Rev 23: 341-366, 1997.

22. Parra E and Ferreira J: Knockdown of the c-Jun-N-terminal kinase expression by siRNA inhibits MCF-7 breast carcinoma cell line growth. Oncol Rep 24: 1339-1345, 2010.

23. Tsuiki H, Tnani M, Okamoto I, Kenyon LC, Emlet DR, Holgado-Madruga M, Lanham IS, et al: Constitutively active forms of c-Jun $\mathrm{NH}_{2}$-terminal kinase are expressed in primary glial tumors. Cancer Res 63: 250-255, 2003.

24. Vivas-Mejia P, Benito JM, Fernandez A, Han HD, Mangala L, Rodriguez-Aguayo C, et al: c-Jun- $\mathrm{NH}_{2}-\mathrm{kinase}-1$ inhibition leads to antitumor activity in ovarian cancer. Clin Cancer Res 16: 184-194, 2010

25. Lovejoy KS, Todd RC, Zhang S, McCormick MS, D'Aquino JA, Reardon JT, Sancar A, Giacomini KM and Lippard SJ cis-Diammine (pyridine)chloroplatinum(II), a monofunctional platinum(II) antitumor agent: uptake, structure, function, and prospects. Proc Natl Acad Sci USA 105: 8902-8907, 2008.

26. Levresse V, Marek L, Blumberg D and Heasley LE: Regulation of platinum-compound cytotoxicity by the c-Jun N-terminal kinase and c-Jun signaling pathway in small-cell lung cancer cells. Mol Pharmacol 62: 689-697, 2002.

27. Helbig L, Damrot J, Hülsenbeck J, Köberle B, Brozovic A, Osmak M, Fiket Z, Kaina B and Fritz G: Late activation of stress-activated protein kinases/c-Jun N-terminal kinases triggered by cisplatin-induced DNA damage in repair-defective cells. J Biol Chem. 286: 12991-13001, 2011.

28. Fritz $G$ and Kaina B: Late activation of stress kinases (SAPK/JNK) by genotoxins requires the DNA repair proteins DNA-PKcs and CSB. Mol Biol Cell 17: 851-861, 2006.
29. Brozovic A, Fritz G, Christmann M, Zisowsky J, Jaehde U, Osmak M and Kaina B: Long-term activation of SAPK/JNK, p38 kinase and fas-L expression by cisplatin is attenuated in human carcinoma cells that acquired drug resistance. Int J Cancer 112: 974-985, 2004

30. Hayakawa J, Depatie C, Ohmichi M and Mercola D: The activation of c-Jun $\mathrm{NH}_{2}$-terminal kinase (JNK) by DNA-damaging agents serves to promote drug resistance via activating transcription factor 2 (ATF2)-dependent enhanced DNA repair. J Biol Chem 278: 20582-20592, 2003.

31. Smeal T, Binetruy B, Mercola D, Grover-Bardwick A, Heidecker G, Rapp UR and Karin M: Oncoprotein-mediated signalling cascade stimulates c-Jun activity by phosphorylation of serines 63 and 73. Mol Cell Biol 12: 3507-3513, 1992.

32. Boyle WJ, Smeal T, Defize L H, Angel P, Woodgett JR, Karin M and Hunter T: Activation of protein kinase $C$ decreases phosphorylation of c-Jun at sites that negatively regulate its DNA-binding activity. Cell 64: 573-584, 1991.

33. Parra E, Ortega A and Saenz L: Down-regulation of Egr-1 by siRNA inhibits growth of human prostate carcinoma cell line PC-3. Oncol Rep 22: 1513-1518, 2009.

34. Parra E, Ferreira F and Saenz L: Inhibition of Egr-1 by siRNA in prostate carcinoma cell lines is associated with decreased expression of AP-1 and NF- $\kappa$ B. Int J Mol Med 28: 847-853, 2011.

35. Parra E, Ferreira J and Ortega A: Overexpression of EGR-1 modulates the activity of NF- $\kappa \mathrm{B}$ and AP-1 in prostate carcinoma PC-3 and LNCaP cell lines. Int J Oncol 39: 345-352, 2011.

36. Inostroza J, Sáenz L, Calaf G, Cabello G and Parra E: Role of the phosphatase PP4 in the activation of JNK-1 in prostate carcinoma cell lines PC-3 and LNCaP resulting in increased AP-1 and EGR-1 activity. Biol Res 38: 163-178, 2005.

37. Yu JJ, Li Q and Reed E: Comparison of two human ovarian carcinoma cell lines (A2780/CP70 and MCAS) that are equally resistant to platinum, but differ at codon 118 of the ERCC1 gene. Int J Oncol 16: 555-560, 2000.

38. Ma FY, Flanc RS, Tesch GH, Han Y, Atkins RC, Bennett BL, Friedman GC, Fan JH and Nikolic-Paterson DJ: A pathogenic role for c-Jun amino-terminal kinase signaling in renal fibrosis and tubular cell apoptosis. J Am Soc Nephrol 18: 472-484, 2007.

39. Vivanco I, Palaskas N, Tran C, Finn SP, Getz G, Kennedy NJ, Jiao J, Rose J, Xie W, Loda M, et al: Identification of the JNK signaling pathway as a functional target of the tumor suppressor PTEN. Cancer Cell 11: 555-569, 2007.

40. Cellurale C, Girnius N, Jiang F, Cavanagh-Kyros J, Lu S, Garlick DS, Mercurio AM and Davis RJ: Role of JNK in mammary gland development and breast cancer. Cancer Res 72: 472-481, 2012.

41. Burgess GS, Williamson EA, Cripe LD, Litz-Jackson S, Bhatt JA, Stanley K, Stewart MJ, Kraft AS, Nakshatri H and Boswell HS: Regulation of the c-jun gene in p210 BCR-ABL transformed cells corresponds with activity of JNK, the c-jun N-terminal kinase. Blood 92: 2450-2460, 1998

42. Raitano AB, Halpern JR, Hambuch TM and Sawyers CL: The Bcr-Abl leukemia oncogene activates Jun kinase and requires Jun for transformation. Proc Natl Acad Sci USA 92: 11746-11750, 1995.

43. Wagner EF and Nebreda AR: Signal integration by JNK and p38 MAPK pathways in cancer development. Nat Rev Cancer 9: 537-549, 2009.

44. Liu J, Minemoto $\mathrm{Y}$ and Lin A: c-Jun N-terminal protein kinase 1 (JNK1), but not JNK2, is essential for tumor necrosis factor alpha-induced c-Jun kinase activation and apoptosis. Mol Cell Biol 24: 10844-10856, 2004.

45. Hayakawa J, Mittal S, Wang Y, Korkmaz KS, Adamson E, English C, Ohmichi M, McClelland M and Mercola D: Identification of promoters bound by c-Jun/ATF2 during rapid large-scale gene activation following genotoxic stress. Mol Cell 16: 521-535, 2004

46. Halazonetis TD, Georgopoulos K, Greenberg ME and Leder P: c-Jun dimerizes with itself and with c-Fos, forming complexes of different DNA binding affinities. Cell 55: 917-924, 1988. 